\title{
DYSTOCIA IN SHEEP AND GOATS: OUTCOME AND FERTILITY FOLLOWING SURGICAL AND NON-SURGICAL MANAGEMENT
}

\author{
Zuhair Bani Ismail \\ Department of Veterinary Clinical Sciences, Faculty of Veterinary Medicine, \\ Jordan University of Science \& Technology, Irbid 22110, Jordan
}

Received 17 September 2016; Received in revised form 9 December 2016; Accepted 10 January 2017

\begin{abstract}
Cesarean section is a life-saving surgical procedure usually undertaken in sheep and goats that fail to deliver vaginally (dystocia). Unfortunately, there are no recent review articles in literature that summarize the results of published case reports and clinical trials concerning indications, surgical approaches and procedures and outcomes following cesarean section in sheep and goats. Therefore, the aim of this article was to compile available data related to dystocia and cesarean section in small ruminants. Fortunately, the incidence of dystocia in small ruminants is considered to be low. It can be caused by either maternal or fetal factors. Maternal-related dystocia is most commonly because of failure of cervical dilation, narrow birth canal and uterine inertia. Those related to fetal causes are usually associated with fetal malposition/presentation, feto-pelvic disproportion/fetal oversize, and fetal malformation. Manual extraction of the fetus may be attempted in most cases, however, early surgical intervention by performing cesarean section ensures satisfactory outcome. Cesarean section is usually performed in lateral recumbency through left paralumbar fossa or left paralumbar fossa oblique celiotomy under local analgesia. The success rates and post-operative complications in sheep and goats are underreported; however, early surgical intervention using aseptic technique usually results in a satisfactory outcome for both the dam and newborn with acceptable prognosis for future breeding soundness.
\end{abstract}

Key words: dystocia, small ruminants, survival, breeding soundness

\section{INTRODUCTION}

Dystocia in small ruminants is considered of low incidence worldwide $(<5 \%)(1-4)$. Dystocia usually occurs when the first or second stages of parturition are delayed or when the first stage fail to progress to the next stage within 30 minutes (26). The normal parturition process is well described in small ruminants $(5,6,7)$. The first stage usually starts when the animal isolates itself from the rest of the herd, shows signs of restlessness, and loss of appetite. Forceful abdominal contractions become stronger and more frequent toward the end of this

Corresponding author: Dr. Zuhair Bani Ismail, $\mathrm{PhD}$

E-mail address: zuhair72@just.due.jo

Present address: Department of Veterinary Clinical Sciences, Faculty of Veterinary Medicine, University of Science \& Technology, Irbid 22110,

Jordan

Phone: ++00962 796654331

Copyright: (C) 2017 Ismail Z.B. This is an open-access article published under the terms of the Creative Commons Attribution License which

permits unrestricted use, distribution, and reproduction in any medium, provided the original author and source are credited.

Competing Interests: The authors have declared that no competing

interests exist.

Available Online First: 17 January 2017

Published on: 15 March 2017

http://dx.doi.org/10.1515/macvetrev-2017-0012 stage. The second stage of parturition marks the expulsion of the fetus which usually occurs within 15-30 minutes. The third stage of parturition follows and ends by the expulsion of the fetal membranes which usually takes place within 4-6 hours (1-7).

\section{CAUSES OF DYSTOCIA}

Close observation of the ewe and doe during parturition is essential for timely interference. Early recognition and interference in cases of dystocia will result in a satisfactory outcome both for the dam and the neonate.

Dystocia in small ruminants can be caused by either maternal or fetal factors (Table 1). In a study involving 70 sheep and goats suffering from dystocia, the highest prevalence was recorded in primiparous females, during the winter season and in dams carrying large male fetuses (4). Fetalrelated causes of dystocia were far more represented in this case population compared to maternal causes (54\% vs. $37 \%)$. The most common fetal-related 
Table 1. A review of risk factors and causes of dystocia in sheep and goats

\begin{tabular}{|c|c|c|c|}
\hline Risk factors & Origin of dystocia & Description & References \\
\hline \multirow[b]{2}{*}{$\begin{array}{l}\text { - Primiparous females } \\
\text { - Winter season } \\
\text { - Dams carrying male fetuses }\end{array}$} & Maternal & - Ringwomb & \multirow[b]{2}{*}{$\begin{array}{l}\text { Bhattacharyya et al. } \\
\text { (4) }\end{array}$} \\
\hline & Fetal & $\begin{array}{l}\text { - Head deviation } \\
\text { - Forelimb flexion } \\
\text { - Breech presentation } \\
\text { - Dog sitting position } \\
\text { - Fetal malformation }\end{array}$ & \\
\hline \multirow[b]{2}{*}{ - Primiparous females } & Maternal & - Ringwomb & \multirow[b]{2}{*}{ Kumar et al. (9) } \\
\hline & Fetal & $\begin{array}{l}\text { - Feto-pelvic disparity } \\
\text { - Fetal emphysema } \\
\text { - Fetal malformation }\end{array}$ & \\
\hline \multirow[t]{2}{*}{ - Yearlings and primiparous females } & Maternal & $\begin{array}{l}\text { - Ringwomb } \\
\text { - Uterine torsion } \\
\text { - Narrow pelvis } \\
\text { - Uterine inertia }\end{array}$ & \multirow[t]{2}{*}{ Sharma et al. (3) } \\
\hline & Fetal & $\begin{array}{l}\text { - Maldisposition } \\
\text { - Fetal malformation } \\
\text { - Oversized fetus }\end{array}$ & \\
\hline \multirow[t]{2}{*}{ - Primiparous females } & Maternal & $\begin{array}{l}\text { - Ringwomb } \\
\text { - Narrow pelvis } \\
\text { - Uterine torsion } \\
\text { - Uterine inertia } \\
\text { - Uterine torsion }\end{array}$ & \multirow[t]{2}{*}{ Ali (8) } \\
\hline & Fetal & $\begin{array}{l}\text { - Fetal maldisposition } \\
\text { - Fetal oversize } \\
\text { - Malformations } \\
\text { - Twins }\end{array}$ & \\
\hline \multirow[b]{2}{*}{ - Young females } & Maternal & - Narrow and small pelvis & \multirow[b]{2}{*}{ Hussain and Zaid (10) } \\
\hline & Fetal & $\begin{array}{l}\text { - Lateral deviation of head and neck } \\
\text { - Bilateral shoulder flexion } \\
\text { - Fetal oversize }\end{array}$ & \\
\hline
\end{tabular}

causes of dystocia were head deviation, forelimb flexion, breech presentation, dog sitting position and fetal malformations. Maternal causes were mostly associated with failure of cervical dilation or ringwomb (4).

In another retrospective study (3), faulty maldisposition, fetal malformation and oversized fetus were the main fetal-related causes of dystocia in sheep and goats. Maternal causes included incomplete cervical dilatation, uterine torsion, narrow pelvis and uterine inertia. It was also reported that more than $60 \%$ of dystocia was diagnosed in yearlings or primiparous females (3).

In one study, the most important causes of dystocia in sheep were ringwomb, narrow pelvis, fetal mal-disposition, and fetal oversize (8). Other less important causes were uterine torsion, monsters and simultaneous presentation of twins (8). In goats, the author reported that ringwomb, fetal maldisposition, narrow pelvis and simultaneous presentation of twins were the major causes of dystocia (8). Other minor causes in goats were uterine inertia, fetal oversize, uterine torsion, and monsters (8).

In another study, it was reported that the most common causes of dystocia that required caesarean section in sheep and goats were incomplete cervical dilatation, feto-pelvic disparity, fetal emphysema, and fetal monsters. The authors also reported that most dystocia cases were diagnosed in primiparous females (9).

Causes of dystocia involving 40 goats were reported in one study (10). All goats were young (1-2.5 years old) (10). In $80 \%$ of the cases, a single large fetus was involved in dystocia and almost $60 \%$ were males (10). Twin pregnancies were about $20 \%$ of the population (10). The most common causes of dystocia were lateral deviation of the head and neck, bilateral shoulder flexion, 
fetal oversize, and narrow and small pelvis of the dam (10).

\section{NON-SURGICAL INTERVENTION}

Methods that could be used for manual assistance of birthing in small ruminants largely depend on the cause of dystocia $(5,6,11,12)$. In cases of ringwomb, manual dilation is usually futile and may result in severe damage to the birth canal.

Various medical and hormonal therapies, and surgical procedures have been used to treat ringwomb with variable success $(8,12)$. Prostaglandin $\mathrm{E}_{2}$ gels and relaxin have shown no beneficial effects in ewes $(8,13)$. In goats, calcium borogluconate and/or estradiol benzoate have shown satisfactory results $(8,12)$.

The administration of prostaglandin $\mathrm{F}_{2 \alpha}(15 \mathrm{mg}$ dinoprost tromethamine or lutalyse) intramuscularly to ewes and does with ringwomb and dead fetuses resulted in complete cervical dilation in $22 \%$ of ewes and $69 \%$ of does within a mean time of 63 hour and 42 hour for ewes and does, respectively (8).

In a case series of 70 small ruminants treated for dystocia due to ringwomb, hormonal treatment using valethamate bromide $(15 \mathrm{mg})$ and cloprostenol sodium $(250 \mu \mathrm{g})$ was successful in $33 \%$ of cases (4). The fetuses could be delivered by obstetrical mutation and extraction method in $51 \%$ of cases and by caesarean section in the remaining cases $(16 \%)(4)$.

It was reported that all goats suffering from dystocia due to lateral deviation of the head and neck $(n=20)$ were treated successfully by mutation and forced extraction (10). In goats with dystocia due to bilateral shoulder flexion associated with absolute fetal oversize, treatment was successful using partial fetatomy by removing the forelimbs from the shoulder region. However, in goats suffering from dysocia due to relative fetal oversize or narrow and small pelvis of the dam, caesarean section was performed (10).

It is important to emphasize here the idea that extensive attempts at manual delivery of the fetus are associated with poorer outcomes in relation to both dam and newborn survival. Furthermore, the diameter of the birth canal of small ruminants is small, making manual manipulation of the fetus very difficult (11). Ideally, in cases where there is a complete dilation of the cervix, a decision should be made if the size of the fetus allows its passage through the birth canal without causing extensive damage using traction. In cases where retention of parts of the fetus are the cause of dystocia, repulsion, mutation and traction may be applied, usually with little success, therefore cesarean section must be undertaken as soon as possible.

\section{PRE-OPERATIVE EVALUATION AND PREPARATION}

A full physical examination including vaginal examination by palpation and transabdominal ultrasonography, and sometimes radiography must be carried out to determine the health status of the dam, the status of the birth canal especially the degree to which the cervix has dilated and the viability of the fetus $(6,11)$. For vaginal examination, proper obstetrical preparation by cleansing, disinfecting and lubricating of the vulva are recommended.

Pre-operatively, intravenous fluid therapy using crystalloid balanced electrolyte solutions with 5\% dextrose must be administered to animals showings signs of cardiovascular compromise and dehydration (9). Pre-operative non-steroidal antiinflammatory drugs such as flunixine meglumine $(1.1 \mathrm{mg} / \mathrm{kg})$ or meloxicam $(0.5 \mathrm{mg} / \mathrm{kg})$ can be administered (9). Pre-operative antibiotics such as ceftiofur $(1 \mathrm{mg} / \mathrm{kg})$ or penicillin $(22000 \mathrm{IU} / \mathrm{kg})$, tetanus toxoid and dexamethasone $(2 \mathrm{mg} / \mathrm{kg})$ are also indicated $(6,9,11)$.

\section{SURGICAL APPROACHES AND ANESTHESIA}

Cesarean section in small ruminants is usually performed while the animal is in right lateral recumbency under local analgesia, with or without sedation $(1,4,6,9,11,14)$. Less frequently, dorsal recumbency under general anesthesia is utilized. Using the lateral approach, a skin incision can be made through the left paralumbar fossa, low flank or ventrolateral, or lateral oblique $(1,6$, 11). In dorsal recumbency, the incision is made in the ventral midline or paramedian regions. Alternatively, the ewe or doe may be positioned in a $45^{\circ}$ angle between the sternal and right lateral side to facilitate exposure of the left flank $(1,6,11)$.

For paralumbar fossa laparotomy (Fig. 1), local infiltration of analgesia using $1 \%$ lidocaine and using line block, inverted L block or paravertebral block can be used. Small ruminants are at a higher risk for lidocaine toxicity which may occur at $5 \mathrm{mg} /$ $\mathrm{kg}$ of body weight or higher doses $(1,4,6)$. 


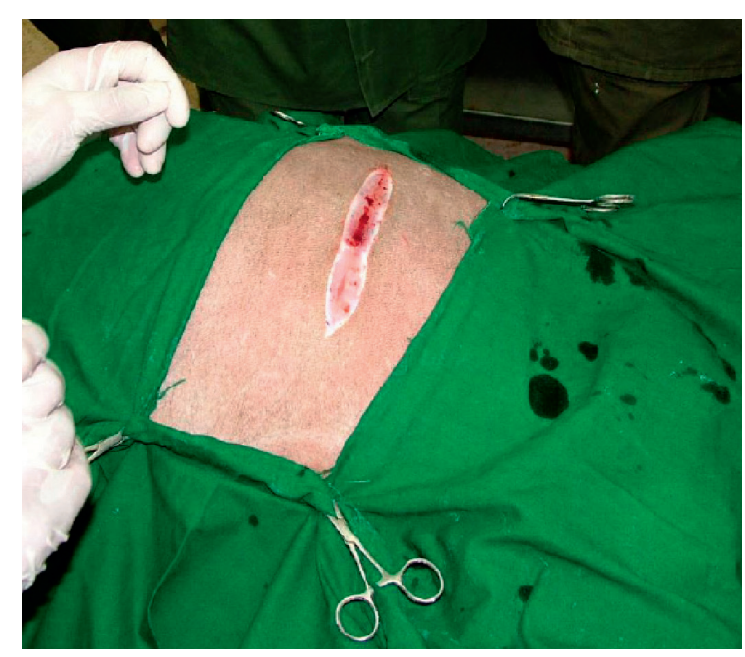

Figure 1. Cesarean section in a sheep. Right lateral recumbency with a left paralumbar fossa incsion is made under sedation and local analgesia

Sedation is sometimes indicated to facilitate positioning of the ewe or doe for surgery. However, it is not recommended if live fetuses are expected because of possible severe cardiopulmonary and nervous depression. Intravenous administration of diazepam or medazolam $(0.2-0.3 \mathrm{mg} / \mathrm{kg}$ for either drug) or xylazine $(0.02-0.2 \mathrm{mg} / \mathrm{kg})$ can be used for short period of sedation in small ruminants $(1,4,6)$.

\section{SURGICAL PROCEDURE}

Appropriate surgical preparation for aseptic surgery is indicated. After opening of the abdominal wall, the gravid horn must be exteriorized using fetal extremities $(6,9)$. Care must be exercised to prevent uterine wall rupture and spillage of contaminated fetal fluid into the abdominal cavity in cases of a dead fetus or delayed dystocia. It is advisable to pack the exteriorized uterus using sterile and moist towels in those situations (Fig. 2). A long incision is made in the greater curvature of the uterus in an area devoid of cotyledons. In most cases, one incision in the uterine horn is used to deliver multiple fetuses $(6,9)$. Otherwise a second incision may be made in the other horn. After delivery of all fetuses in both horns, loosely attached fetal membranes are cut and the uterine incision is closed using a single (live fetus) or double layer (dead or emphysematous fetus) of inverting suture pattern such as Utrecht or Lambert techniques using size 0 or 1 absorbable suture material $(6,9)$. The uterus is then flushed copiously using sterile saline with a disinfectant or antibiotic solution added to the flush solution to remove all blood clots to prevent adhesion formation. The peritoneum and muscle layers are then closed using size 1 absorbable suture material in a simple continuous pattern. The skin is closed using size 1 non-absorbable sutures in simple interrupted fashion $(6,9)$.

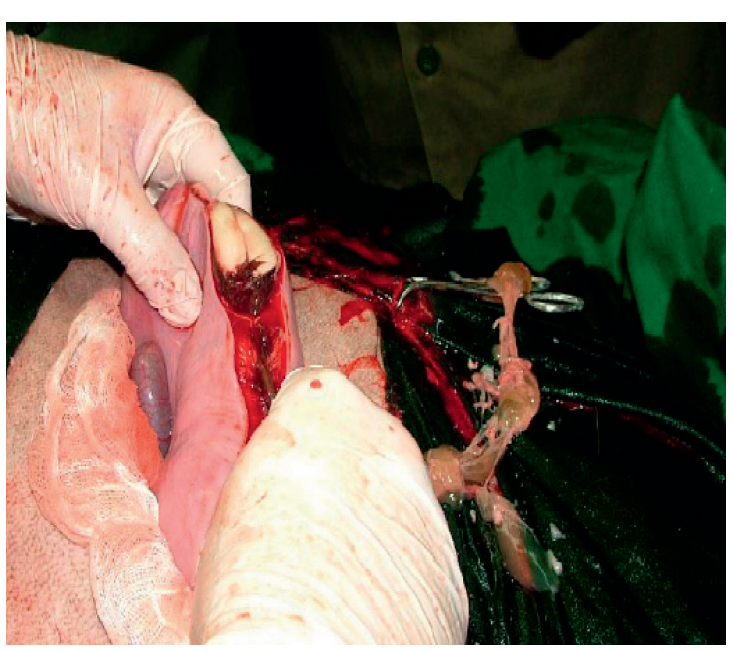

Figure 2. Cesarean section in a sheep. Exteriorization of the gravid horn is made and the abdominal cavity is protected by packing using a sterile gauze. The uterine incision is made over a non-vascularized part of the uterine horn

\section{POST-OPERATIVE CARE}

Intrauterine pessaries containing antibiotics (penicillin or oxytetracycline) are sometimes placed inside the uterus before closure is commenced (9). Systemic post-operative antibiotics and nonsteroidal anti-inflammatory drugs must continue for 5 to 7 days $(6,9)$. Suitable systemic antibiotics may include procaine penicillin G (22000 IU/kg), ceftiofur $(1 \mathrm{mg} / \mathrm{kg})$, or tetracycline $(20 \mathrm{mg} / \mathrm{kg})$. Flunixine meglumine $(1.1 \mathrm{mg} / \mathrm{kg})$ or meloxicam $(0.5 \mathrm{mg} / \mathrm{kg})$ are commonly used in sheep and goats (9). Skin sutures are removed in 10-14 days postoperatively $(6,9)$.

\section{POST-OPERATIVE COMPLICATIONS AND OUTCOME}

Little information is available in literature concerning post-operative complications, outcomes and future fertility in small ruminants after dystocia 
and cesarean section. Generally, the outcome and success rates are much higher if surgery was performed early when the fetus is alive or freshly dead (10). Survival of both the dam and newborn were significantly affected by the length of time delay between the start of labor and the time of presentation for surgical intervention $(1,3)$.

It has been reported that the most common complication following surgery was retained placenta, which was more likely to occur in ewes that received prolonged assistance before surgery $(3,15)$. Moreover, it was reported that vaginal tear and secondary uterine inertia (hypocalcemia) are common in non-surviving sheep and goats undergoing surgery for dystocia (3). They concluded that these complications were related to unsuccessful handling of cases before surgery.

It was reported that fetal and dam survival rates in sheep and goats undergoing cesarean section were $23 \%$ and $94 \%$ respectively (4). The most common complications reported in this study were acute fatal peritonitis associated with uterine tear during surgery, retained fetal membranes, and acute metritis (4). Vaginal or uterine tears are common in cases with delayed surgical intervention, excessive pre-operative manipulation or mishandling $(14,16)$.

\section{FUTURE FERTILITY}

There is very little scientific information regarding future fertility in ewes and does that underwent cesarean section. In general, the prognosis for future fertility in sheep and goats is good when minimum vaginal manipulation was performed before prompt referral for surgical intervention. It was reported that out of 85 sheep and 25 goats, 16 were rebred and all of them became pregnant (1).

\section{CONCLUSION}

Prolonged dystocia in sheep and goats and unnecessary and prolonged attempts for vaginal delivery seriously affect the case outcome. Early intervention by performing cesarean section can result in the delivery of live lambs and kids and much healthier dams.

\section{CONFLICT OF INTEREST STATEMENT}

The authors declared that they have no potential conflict of interest with respect to the authorship and/or publication of this article.

\section{REFERENCES}

1. Brounts, S.H., Hawkins, J.F., Baird, A.N., Glickman, L.T. (2004). Outcome and subsequent fertility of sheep and goats undergoing cesarean section because of dystocia: 110 cases (1981-2001). J. Am. Vet. Med. Assoc. 224, 275-279.

https://doi.org/10.2460/javma.2004.224.275

PMid:14736074

2. Purohit, G.N. (2006). Dystocia in the sheep and goat. A review. Indian J. Sm. Rum. 12(1), 1-12.

3. Sharma, A., Kumar, P., Singh, M., Vasishta, N. (2014). Retrospective analysis of dystocia in small ruminants. Intas Polivet. 15, 287-289.

4. Bhattacharyya, H.K., Fazili, M.R., Bhat, F.A., Buchoo, B.A. (2015). Prevalence and dystocia of sheep and goats: A study of 70 cases (2004-2011). J. Adv. Vet. Res. 5, 14-20.

5. Noakes, D.E., Parkinson, T.J., England, G.C.W. (2009). Noakes's' veterinary reproduction and obstetrics. London, Saunders.

6. Fubini, S.L., Ducharme, N.G. (2004). Farm animal surgery. Missouri, Saunders.

7. Menzies PI, Bailey D (1997). Current therapy in large animal theriogenology. Philadelphia, Saunders.

8. Ali, A.M.H. (2011). Causes and management of dystocia in small ruminants in Saudi Arabia. J. Agri. Vet. Sci. 4(2), 95-108.

9. Kumar, V., Talekar, S.H., Ahmad, R.A., Mathew, D.D., Zama, M.M.S. (2013). Delayed cases of dystocia in small ruminants - etiology and surgical management. Indian J. Vet. Sci. 1, 47-54.

10. Hussain, S.O., Zaid, N.W. (2010). Dystocia in goats, causes and treatment. AL-Qadisiya J. Vet. Med. Sci. 9.

11. Fubini, S., Heath, A.M., Pugh, D.G. (2002). Sheep and goat medicine. Philadelphia, Saunders. PMCid:PMC2173981

12. Hanie, E.A.A. (2006). Large Animal Clinical Procedures for Veterinary Technicians. Elsevier, Mosby, Missouri. 
13. Wu, W.X., Xiao, Hong. M,A., Coksaygan, T., Chakrabarty, K., Collins, K.V., Rose, J., Nathanielsz, P.W. (2004). Prostaglandin mediates premature delivery in pregnant sheep induced by estradiol at 121 days of gestational age. Endocrinol. 45, 1444-1452. https://doi.org/10.1210/en.2003-1142 PMid:14645114

14. Muir, W.W., Hubbell, J., Skarda, R.T., Swanson, C.R., Mason, D.M. (2000). Handbook of veterinary anesthesia. Elsevier, Mosby, Missouri.
15. Leontides, L., Fthenakis, G.C., Amiridis, G.S. (2000). A matched case-control study of factors associated with retention of fetal membrane in dairy ewes in southern Greece. Prev. Vet. Med. 44, 113-120. https://doi.org/10.1016/S0167-5877(99)00115-4

16. Kenneth, D.N. (2008). Bovine cesarean section in the field. Vet. Clin. North. Am. Food. Anim. Pract. 24, 273-293.

https://doi.org/10.1016/j.cvfa.2008.02.009

PMid:18471569

Please cite this article as: Ismail Z.B. Dystocia in sheep and goats: outcome and fertility following surgical and non-surgical management. Mac Vet Rev 2017; 40 (1): 91-96. http://dx.doi.org/10.1515/macvetrev-2017-0012 